\title{
On Current Conditions of Pronunciation Teaching and Learning under Occupation-Related Criterion
}

\author{
Qian Liu \\ School of Foreign Languages, Linyi University \\ Shuangling Road, Linyi Shandong 276005, China \\ Tel: 86-539-215-8360 E-mail: Liuqian@lyu.edu.cn
}

Received: June 17, 2011

Accepted: June 30, 2011

Published: December 1, 2011

doi:10.5539/ells.v1n2p2

URL: http://dx.doi.org/10.5539/ells.v1n2p2

\begin{abstract}
This study aims to investigate the current conditions of pronunciation teaching and learning in a local university through a questionnaire. The subjects majoring in English Education agree that accuracy rather than intelligibility should be adopted as the criterion for English teachers. Though the importance of pronunciation is well recognized by the subjects, instruction lags far behind the learners' requirements. Different approaches beneficial for pronunciation learning are also ascertained on the part of learners. Findings suggest that instruction innovation is urgent and competent bilingual teachers should be trained to meet the needs of pronunciation teaching.
\end{abstract}

Keywords: Pronunciation, Accuracy, Intelligibility, Instruction innovation

\section{Introduction}

Grammar-translation method and communicative language teaching are the two major currents that run through our EFL courses. The first current focuses upon elements of accuracy in written work, while the second emphasizes fluency in speaking. Unfortunately, both of them neglect to address adequately issues related to gaining accurate control over pronunciation. Nevertheless, foreign language professionals must be cautioned that numerous learners might be impaired through their exposure to the inaccurate pronunciation. Concerning the seriousness of this issue, Baldwin (as quoted by Carey, 2004) has ever made the following observation in a study of natural continuous Japanese second language (SL) speech: "I sink zat people are bery kind". It is observed in the teaching practices that some advanced Chinese English learners also make the substitution mistakes cited above, usually with the difference that wery is pronounced instead of bery.

Many researchers (e.g., Dalton, 1997) maintain that insisting on correct pronunciation may not always be desirable and may not be feasible either, particularly with older learners. In this case, Kenworthy (1987) argues that occupation-related criterion should be utilized. Though it may be unrealistic, as Morley (1991) claims, for the foreign language teachers to strive for perfect pronunciation, they ought to aim for the closest approximation to accuracy because of the very nature of their future occupation. Nevertheless, due attention has been paid neither to pronunciation teaching nor to the pronunciation criterion that should be adopted by the instructors in the teaching practices of many universities. Therefore, taking a local university as a sample, we intent to investigate the current condition of pronunciation teaching and learning through a questionnaire so as to gain further insights and thus promote teaching innovation in this aspect.

\section{Research}

\subsection{The design of questionnaire and results of test}

The questionnaire designed is composed of 22 items (see Appendix One). Likert-Scale is adopted in this questionnaire, with the choice of 1 meaning the maximum disagreement, whereas the choice of 5 the maximum agreement. 120 juniors of four classes majoring in English Education in Linyi University, Shandong province attended this test. It should be noted that no phonetics courses had been offered to these undergraduates when the research was conducted. Altogether 7 invalid returns of the questionnaire were not included in the analysis because of omission of choices or revision of stems of particular items. Then the data obtained from the remaining 113 returns were analyzed by SPSS. Consequently, item analysis shows that items 1 and 3 should be deleted, for independent samples test signifies their lower significance rate (sig.>.05). Then the remaining 20 items attends factor analysis and four main categories are identified (see Appendix Two). The first category, including items 8, 9, 
10 and 11, can be named instructional variables, with its Alpha $=0.8085$. The second category, including items 17 , 18 and 19, can be named needs variables, with its Alpha $=0.7026$. The third category, including items 12,13 , and 15, can be named learning variables, with its Alpha $=0.6640$. The last one, including items 20,21 , and 22, can be named improvement variables, with its Alpha $=0.6097$. In addition, reliability analysis shows that the reliability coefficients of the whole questionnaire is Alpha $=0.7887$. The selection results of the questionnaire are illustrated in Table 1.

\subsection{Analysis of the questionnaire}

As is mentioned earlier, altogether 13 items in the questionnaire are assigned to 4 main categories by factor analysis. Apart from items 1 and 3 that are excluded by item analysis, there are still 7 items left, among which items 4, 5, 6 and 7 are designed to ascertain the subjects' opinions on their teachers' pronunciation, while items $2,14,16$ are about their cognition on the importance of pronunciation and evaluation on their own pronunciation learning. In addition to the detailed analysis of the 4 main categories, a scrutiny on the 7 items might also provide valuable information to our investigation.

The teachers' pronunciation - intelligibility or accuracy. Generally speaking, intelligibility is considered to be a more reasonable goal for adult English learners. Nevertheless, problem arises if this is also adopted as a criterion for the teachers' pronunciation, for they act as the medium by which English pronunciation is communicated to the pupils. In the questionnaire, item 4 is designed to seek for an answer to this issue from the students. With the highest mean of 4.8496 among all the 22 items, it is clear that accuracy, instead of intelligibility, is also adopted by the subjects as a goal that every teacher should manage to attain. Though accuracy is set as a criterion that every teacher is expected to meet, it is a pity that most of the teachers' performances in pronunciation are judged to be disappointing by the subjects (see the result of item 7). And more than $94 \%$ of the subjects suggest that most teachers should improve their pronunciation accuracy, which can be seen from the result of item 6 . That is to say, a teacher's pronunciation which is intelligible for some learners may turn out to be difficult to tolerate for the others. That's the reason why some learners are often heard complaining of their teachers' inaccurate pronunciation, whereas other learners do not seem to care much. Eventually, those intolerant learners may refuse to listen to the inaccurate utterances and this can be confirmed by the finding of item 5 , with nearly $93 \%$ of the subjects indicating that their enthusiasm in class might be reduced by a teacher's inaccurate pronunciation.

The subjects' cognition on the importance of pronunciation and evaluation on their own pronunciation learning. The result of item 2 shows that nearly $90 \%$ of the students think that pronunciation will have an important impact on their future study and work. Therefore, the importance of pronunciation is well recognized by most of them. However, it should still be noted that about $10 \%$ of the subjects do not share this view. Having not realized the significant role that pronunciation will play, they might not be interested in relevant instruction and might not pay attention to monitoring their pronunciation either. As Cook (2001) points out, high motivation is one factor that causes successful learning, thus these learners might be those who will benefit little from pronunciation teaching.

As undergraduates majoring in English education, most of the subjects will become English teachers in the near future. Therefore, accuracy should also be a goal that they should achieve. However, an examination of item 16 reveals that only $39 \%$ of the subjects are satisfied with their own pronunciation. Fortunately, only a minority of them $(19.5 \%)$, as is shown by the result of item 14, insist that it is difficult for them to correct their pronunciation mistakes. Pennington (as cited in Celce-Murcia et al., 1996) suggests that there exist three barriers to pronunciation improvement from the perspective of the learners: physiological (I cannot change), psychological (I do not need to change) and sociological (I don't think it's good to change). Encouragingly it is seen from the analysis above that these barriers may not pose much threat to an overwhelming majority of the subjects against their improvement of pronunciation. Having recognized the significance of accurate pronunciation for a teacher and realized their disadvantages in this aspect, the subjects, confident of their capability in changing, are in urgent need of improving their pronunciation accuracy.

The instruction provided. Items $8,9,10$ and 11 are concerned with the present conditions of pronunciation instruction that the subjects are exposed to. Though nearly half of the subjects (45.2\%) admit that their teachers often emphasize the importance of pronunciation, most of them point out the inefficiency of pronunciation teaching. For instance, nearly $74 \%$ of them posit that their teachers seldom impart relevant knowledge to them and an overwhelming majority of them also report that their teachers neither remind them of their pronunciation mistakes nor correct them. In effect, this phenomenon might result from the inadequacy of phonetics knowledge on the part of teachers. Educated in the traditional grammar-translation classroom, most of them are also the victim of conscious or unconscious neglect of pronunciation.

The subjects' needs in instruction. In the questionnaire, items 17, 18, 19 investigate the subjects' expectation for 
pronunciation instruction. Though the current popular pedagogy - the communicative approach does not see a need to impart rules and correct errors (Hammerly, 1991), the significance of learning pronunciation rules and correcting pronunciation mistakes is recognized by the subjects, with $83.2 \%$ of them hoping to receive explicit and systematic rule instruction and $97.3 \%$ of them expecting the teachers to point out their mistakes and help them with their correction. In addition, $92.9 \%$ of them hope that pronunciation exercises can be increased. Due to the urgent need of the learners and the incapability of the instructors, relevant courses should be offered and large quantity of qualified phonetics teachers should be trained so as to meet the requirement on pronunciation teaching.

The subjects' present pronunciation learning. Items 12, 13, and 15 constitute another main category in the questionnaire, which is related to the subjects' learning situation. The result of item 12 indicates that more than $50 \%$ of the students often imitate standard pronunciation from various channels. The finding of item 13 shows that about $72 \%$ of the learners often examine whether they themselves have produced inaccurate pronunciation. $84 \%$ of the subjects think that they have made considerable progress compared with their performances in high school. Though the subjects' needs in pronunciation instruction are largely neglected by the teaching practices, it is encouraging to notice that most of the learners, according to their claim, attach much importance to their pronunciation learning and positive effect has been achieved. However, it should still be noted that some individuals do not seem to make any effort in this aspect though accuracy is identified as a goal that every teacher should strive for.

Ways of improvement. The last three items in the questionnaire are about possible ways of improving pronunciation accuracy. Item 20 is concerned with the role of peer evaluation in improving pronunciation. Celce-Murcia et al. (1996) posits that it is useful to have peers serve as both monitors and givers of feedback, for this helps to put their knowledge of pronunciation rules to immediate use. With a mean of 4.44159 , it seems that the positive role of peer evaluation is also expected by the subjects. It is well known that examination has exerted its great influence in Chinese educational system. Therefore, an inclusion of pronunciation test might contribute indirectly to the subjects' improvement in pronunciation accuracy. The result of item 21 suggests that this speculation is affirmed by $71 \%$ of the subjects. However, it should be noted that some students, though having realized its positive influence, might still give this item a negative answer because of their unwillingness to attend extra examinations. The last item in the questionnaire is about the effect of monitoring under the guide of pronunciation rules. An examination of its result reveals an overwhelming confirmation, with $96.5 \%$ of the learners expecting its benefit for pronunciation accuracy.

\section{Implications}

Forming good habits from the very start. Though it is confirmed in this study that still much can be done to enhance the so-called fossilized pronunciation of adult learners, the remedial work does not prove to be easy for most learners, because they might easily slip back into their habitual mispronunciation in spontaneous speech. Therefore, language learners should be encouraged to form good habits from the very start of their learning, which, according to Hammerly (1991), can produce much better results than trying to correct long-standing, habitual pronunciation problems years later.

\subsection{Raising the learners' motivation}

As is observed from the results of the questionnaire, there are still some students who do not seem to care much about whether their pronunciation is accurate or not. Though the causes of their neglect vary from individual to individual, Kenworthy (1987) argues that attempts to improve pronunciation will have little chance of success unless the learners' indifference is counter-balanced in some way. Therefore, the concern about pronunciation should be strengthened to some degree by the teachers. First, the instructors should emphasize the significance of accurate pronunciation and pay attention to the learners' progress in it, which might instil a similar concern in the learners themselves. Second, the teachers should help the learners recognize that they have a responsibility beyond intelligibility. As undergraduates majoring in English education, these potential teachers are not expected to impair their learners' pronunciation with their own inaccurate utterances. Last but not least, testing, a traditional tool whose effect has been recognized by most learners, could be utilized by the teachers to arouse the learners' enthusiasm for pronunciation.

\subsection{Training competent bilingual teachers}

Generally speaking, most English learners in China are instructed in classrooms where pronunciation is never a teaching focus. Therefore, it might be difficult for them to form good pronunciation habits. However, their needs in accurate pronunciation should never be neglected, for they may continue in their misperception and inaccurate production if the differences between target sounds and those they perceived are not pointed out to them. Therefore, qualified bilingual teachers are needed to improve the effectiveness of pronunciation teaching. This point is also approved by Hammerly (1991), claiming that a strictly phonetic, monolingual approach to pronunciation is not as effective as one that considers both target sounds and their NL counterparts. Though it is not difficult for language 
teachers to give lessons in English, few, according to the information obtained from the questionnaire, could distinguish themselves as qualified pronunciation teachers. Therefore, the urgent need of training competent bilingual teachers should be recognized so as to help the learners with their improvement in pronunciation.

\subsection{Questions that should be noted in instruction}

As is shown by the investigation, most subjects realize that they do not acquire accurate pronunciation and they attempt to make some changes. However, it is difficult for them to accomplish the target-like pronunciation due to the phenomenon of negative transfer that is rampant in pronunciation learning. That is to say, the learners might perceive a specific target sound according to the pronunciation of a similar Chinese sound and they might not discern crucial distinctions between them. Therefore, the teachers should help the learners to recognize the differences between target sounds and those they perceive through the explanation of pronunciation rules. Even if the learners might finally discern the differences, they need to practice the desired sounds under the guide of pronunciation rules. In addition, some researchers (Jones, 1997; Hammerly, 1991) argue that target sounds should be practiced from the communicative perspective so as to go beyond meaningless drill and to help the learners integrate them into their creative speech.

\section{Conclusion}

Undergraduates majoring in English education are expected to pronounce accurately in view of the particularity of their future profession. Nevertheless, our investigation shows that the present pronunciation teaching and learning is far not satisfactory due to the interplay of many factors and thus calls for innovation in relevant aspects urgently. However, it should be noted that the participants involved in this research are from the same local university. In addition, the items designed in the questionnaire might not cover the full range of pronunciation teaching and learning. Therefore, due to the limitation of this small scale research, we are not sure whether this investigation might reflect the commonality of the present pronunciation teaching and learning and it is still subject to the examination of relevant researches.

\section{References}

Carey, M. (2004). Pronunciation pedagogy: historical development and traditional classroom practice. [Online] Available: http://clas.mq.edu.au/phonetics/phonology/interlanguage/pronpedagogy.html

Celce-Murcia, M., Brinton, D., \& Goodwin, J. (1996). Teaching pronunciation: reference for teachers of English to speakers of other languages. Cambridge: Cambridge University Press.

Cook, V. (2001). Second language learning and language teaching. London: Hodder Arnold.

Dalton, D. F. (1997). Some techniques for teaching pronunciation. [Online] Available: http://iteslj.org/Techniques/Dalton-Pronunciation.html

Hammerly, H. (1991). Fluency and accuracy: Toward Balance in Language Teaching and Learning. Clevedon: Multilingual Matters.

Jones, R. (1997). Beyond "listen and repeat": pronunciation teaching materials and theories of second language acquisition. System, 25 (1), 103-112. http://dx.doi.org/10.1016/S0346-251X(96)00064-4

Kenworthy, J. (1987). Teaching English pronunciation. New York: Longman.

Morley, J. (1991). The pronunciation component in teaching English to speakers of other languages. TESOL Quarterly, 25 (3), 481-520. http://dx.doi.org/10.2307/3586981 
Table 1. Data obtained from the questionnaire

\begin{tabular}{|c|c|c|c|c|c|c|}
\hline \multirow[b]{2}{*}{ Item } & \multicolumn{5}{|c|}{ Options (\%) } & \multirow[b]{2}{*}{ Mean } \\
\hline & 1 & 2 & 3 & 4 & 5 & \\
\hline Item 1 & 0.9 & 1.8 & 0 & 21.2 & 76.1 & 4.6991 \\
\hline Item 2 & 0 & 3.5 & 7.1 & 37.2 & 52.2 & 4.3805 \\
\hline Item 3 & 0 & 6.2 & 9.7 & 35.4 & 48.7 & 4.2655 \\
\hline Item 4 & 0 & 0 & 0 & 15 & 85 & 4.8496 \\
\hline Item 5 & 0 & 0 & 7.1 & 39.8 & 53.1 & 4.4602 \\
\hline Item 6 & 0 & 0 & 5.3 & 32.7 & 61.9 & 4.5664 \\
\hline Item 7 & 12.4 & 29.2 & 50.4 & 8.0 & 0 & 2.5398 \\
\hline Item 8 & 5.3 & 31.0 & 18.6 & 38.1 & 7.1 & 3.1062 \\
\hline Item 9 & 15 & 58.4 & 15.9 & 9.7 & 0.9 & 2.2301 \\
\hline Item 10 & 12.4 & 40.7 & 15.9 & 26.5 & 4.4 & 2.6991 \\
\hline Item 11 & 13.3 & 43.4 & 20.4 & 20.4 & 2.7 & 2.5575 \\
\hline Item 12 & 4.4 & 15.0 & 28.3 & 33.6 & 18.6 & 3.4690 \\
\hline Item 13 & 1.8 & 10.6 & 15.0 & 54.0 & 18.6 & 3.7699 \\
\hline Item 14 & 1.8 & 17.7 & 30.1 & 39.8 & 10.6 & 3.3982 \\
\hline Item 15 & 2.7 & 3.5 & 9.7 & 51.3 & 32.7 & 4.0796 \\
\hline Item 16 & 7.1 & 24.8 & 29.2 & 37.2 & 1.8 & 3.0177 \\
\hline Item 17 & 0.9 & 8.0 & 8.0 & 35.4 & 47.8 & 4.2124 \\
\hline Item 18 & 0 & 0 & 2.7 & 29.2 & 68.1 & 4.6549 \\
\hline Item 19 & 0 & 0 & 7.1 & 36.3 & 56.6 & 4.4956 \\
\hline Item 20 & 1.8 & 1.8 & 6.2 & 33.6 & 56.6 & 4.4159 \\
\hline Item 21 & 4.4 & 8.8 & 15.0 & 38.1 & 33.6 & 3.8761 \\
\hline Item 22 & 0 & 0.9 & 2.7 & 35.4 & 61.1 & 4.5664 \\
\hline
\end{tabular}

\section{Appendix One: Questionnaire}

This questionnaire aims to investigate your opinions on English pronunciation teaching and learning. Please tick the item that you agree on for the following statement with answers ranging from " 1 " - Maximum Disagreement - to "5" - Maximum Agreement.

1. Pronunciation is an important aspect of English learning. $\begin{array}{rlllll}1 & 2 & 3 & 4 & 5\end{array}$

2. Pronunciation has great influence on my future study and occupation. $\quad \begin{array}{rrrrr}1 & 2 & 3 & 4 & 5\end{array}$

3. Accuracy is as important as fluency for oral English. $\quad \begin{array}{lllll}1 & 2 & 3 & 4 & 5\end{array}$

4. Teachers should acquire accurate pronunciation. $\begin{array}{llllll}1 & 2 & 3 & 4 & 5\end{array}$

5. My mood will be influenced by teachers' inaccurate pronunciation in class. $\quad \begin{array}{rrrrr}1 & 2 & 3 & 4 & 5\end{array}$

6. At present most teachers should improve their pronunciation accuracy. $\quad \begin{array}{llllll}1 & 2 & 3 & 4 & 5\end{array}$

7. At present most teachers have accurate pronunciation. $\quad \begin{array}{lllll}1 & 2 & 3 & 4 & 5\end{array}$

8. Teachers often emphasize the importance of pronunciation. $\quad \begin{array}{rrrrr}1 & 2 & 3 & 4 & 5\end{array}$

9. Teachers often impart pronunciation knowledge to us. $\quad \begin{array}{lllll}1 & 2 & 3 & 4 & 5\end{array}$

10. Teachers often point out our pronunciation mistakes. $\quad \begin{array}{llllll}1 & 2 & 3 & 4 & 5\end{array}$ 
11. Teachers often correct out pronunciation mistakes. $\quad \begin{array}{llllll}1 & 2 & 3 & 4 & 5\end{array}$

12. I often imitate standard pronunciation from movie, radio, TV, etc. $\begin{array}{llllll}1 & 2 & 3 & 4 & 5\end{array}$

13. I check my pronunciation mistakes consciously in daily learning. $\quad \begin{array}{llllll}1 & 2 & 3 & 4 & 5\end{array}$

14. I think it's easy to correct pronunciation mistakes. $\begin{array}{llllll}1 & 2 & 3 & 4 & 5\end{array}$

15. I have made great progress in pronunciation than in middle school. $\begin{array}{lllllll}1 & 2 & 3 & 4 & 5\end{array}$

16. I'm satisfied with my pronunciation. $\quad \begin{array}{llllll}1 & 2 & 3 & 4 & 5\end{array}$

17. I hope teachers might explain pronunciation rules systematically. $\quad \begin{array}{llllll}1 & 2 & 3 & 4 & 5\end{array}$

18. I hope teachers might point out and correct my pronunciation mistakes. $\begin{array}{llllll}1 & 2 & 3 & 4 & 5\end{array}$

19. I hope training and exercises on pronunciation might be added. $\begin{array}{llllll}1 & 2 & 3 & 4 & 5\end{array}$

20. We classmates can help each other to correct our pronunciation mistakes. $\begin{array}{rrrrr}1 & 2 & 3 & 4 & 5\end{array}$

21. Pronunciation tests can promote our pronunciation learning. $\quad \begin{array}{lllll}1 & 2 & 3 & 4 & 5\end{array}$

22. Self-monitoring under pronunciation rules can improve our accuracy. $\begin{array}{llllll}1 & 2 & 3 & 4 & 5\end{array}$

Appendix Two: Factor Analysis

\begin{tabular}{|c|c|c|c|c|c|c|}
\hline \multirow[t]{2}{*}{ Items } & \multirow{2}{*}{$\begin{array}{l}\text { Explained } \\
\text { Variance }\end{array}$} & \multirow{2}{*}{$\begin{array}{l}\text { Cumulative } \\
\text { Explained }\end{array}$} & \multicolumn{4}{|c|}{ Component } \\
\hline & & & $\begin{array}{c}\text { Factor } \\
1\end{array}$ & $\begin{array}{c}\text { Factor } \\
2\end{array}$ & $\begin{array}{c}\text { Factor } \\
3\end{array}$ & $\begin{array}{c}\text { Factor } \\
4\end{array}$ \\
\hline 9 & \multirow{4}{*}{16.198} & \multirow{4}{*}{16.198} & .801 & & .120 & \\
\hline 10 & & & .793 & & & .254 \\
\hline 11 & & & 789 & & .203 & .235 \\
\hline 8 & & & 742 & .222 & 1.53 & \\
\hline 18 & \multirow{3}{*}{15.538} & \multirow{3}{*}{31.736} & 139 & .782 & .105 & .118 \\
\hline 19 & & & & .771 & .325 & \\
\hline 17 & & & & .743 & .142 & .136 \\
\hline 22 & \multirow{3}{*}{14.859} & \multirow{3}{*}{46.595} & 184 & .355 & .811 & .280 \\
\hline 21 & & & 103 & .249 & .670 & .190 \\
\hline 20 & & & 119 & .389 & .545 & .342 \\
\hline 13 & \multirow{3}{*}{13.378} & \multirow{3}{*}{59.415} & 154 & & & .834 \\
\hline 12 & & & 173 & & & .721 \\
\hline 15 & & & & .109 & .240 & 651 \\
\hline $\begin{array}{l}\text { Characteristic } \\
\text { Value }\end{array}$ & & & 2.676 & 2.268 & 2.175 & 2.080 \\
\hline
\end{tabular}

